\title{
Westringa fruticosa (Willd.) Druce Leaf and Flower Extracts Lack Antibacterial Activity and are Non-toxic in vitro
}

\author{
Getmore Chikowe ${ }^{1}$, Lindi Mpala', Ian Edwin Cock ${ }^{1,2, *}$ \\ 'School of Environment and Science, Nathan Campus, Griffith University, 170 Kessels Rd, Nathan, Brisbane, Queensland, AUSTRALIA. \\ 'Environmental Futures Research Institute, Griffith University, 170 Kessels Rd, Nathan, Brisbane, Queensland, AUSTRALIA.
}

\begin{abstract}
Introduction: Closely related plant species often share similar secondary metabolites and bioactivities and are therefore good targets for bioactivity testing when one or more species within a family are known to possess therapeutic properties. The family Laminaceae has a long history of medicinal usage globally. Many species are known to have therapeutic properties, several species of which have well established antibacterial bioactivities. Methods: The ability of Westringa fruticosa leaf and flower extracts to inhibit the growth of a panel of bacterial and fungal pathogens was investigated by disc diffusion assay. Toxicity was examined using the Artemia franciscana nauplii bioassay. Results: $W$. fruticosa leaf methanolic and aqueous extracts were both completely ineffective at inhibiting the growth of gram-positive and gram-negative panels of bacteria, as well as fungi. The extracts were non-toxic or of low toxicity in the Artemia bioassay following $24 \mathrm{~h}$ exposure. Conclusion: Despite the taxonomic relationship to several bioactive Laminaceae spp., W. fruticosa leaf and flower extracts
\end{abstract}

were completely ineffective bacterial and fungal growth inhibitors. However, these extracts may have other therapeutic properties and testing against protozoa, virus and tumour cells is required.

Key words: Lamiaceae, Coastal rosemary, Antibacterial activity, Australian plant, Traditional medicine, Medicinal plants, Toxicity.

\section{Correspondence:}

\section{Dr. Ian Edwin Cock}

${ }^{1}$ School of Environment and Science, Nathan Campus, Griffith University, 170 Kessels Rd, Nathan, Brisbane, Queensland 4111, AUSTRALIA.

'Environmental Futures Research Institute, Griffith University, 170 Kessels Rd, Nathan, Brisbane, Queensland 4111, AUSTRALIA.

Phone no: +61737357637

E-mail: I.Cock@griffith.edu.au

DOI: $10.5530 /$ pc.2019.3.21

\section{INTRODUCTION}

Traditional plant derived medicines have been used in most parts of the world for a variety of therapeutic purposes, including fighting microbial disease. Indeed, the ability of plant extracts to block the growth of pathogenic bacteria has become a focus of substantial recent study. ${ }^{1-5}$ Much of the research into traditional medicinal plant use has focused on Asian, ${ }^{6-8}$ African, ${ }^{9-11}$ Middle Eastern ${ }^{12-14}$ and South American ${ }^{15}$ plants. However, despite the potential of plants to provide us with useful pharmaceutical agents, the field is still relatively poorly studied. Only an estimated 5-10\% of the approximately 300,000-500,000 plant species worldwide have been screened for one or more bioactivities. ${ }^{9}$ With so many plant species yet to be tested, it is essential that plant selection processes narrow the field. The main selection criteria currently used is to select plants on the basis of ethnobotanical usage as traditional medicines. Another important selection method is to examine plants related to plants for which medicinal potential is well established. Many plant secondary metabolites are regarded as family, genus or species specific and investigation of species closely related to those used as traditional medicines may lead to natural therapeutic discoveries. ${ }^{16}$

The development of new antibiotic therapies is particularly urgent. The recent establishment of bacterial pathogens that are either extremely (XDR) or totally resistant (TDR) to common clinically used antibiotics ${ }^{17}$ has resulted in the need to develop new and effective antibiotic chemotherapies. There are now limited therapeutic options for many diseases caused by bacterial pathogens and the situation is expected to worsen in the future as bacteria exchange resistance genes. Indeed, the development of alternative antibacterial treatment modalities has become crucial and is considered by the World Health Organisation (WHO) to be one of the most serious challenges facing medical science. ${ }^{18}$ For a number of reasons reviewed elsewhere, ${ }^{17}$ it is unlikely that the previous methods of antibiotic discovery/development will be as successful in the future and new treatment modalities are urgently required. Traditional medicines and herbal remedies have great potential for antimicrobial drug development and there has recently been a substantial increase in interest in this field. ${ }^{19,20}$

The first Australians had well-developed medicinal systems and understood the therapeutic properties of a wide variety of Australian plants and how to use them effectively. ${ }^{16}$ Despite this, relatively few studies have rigorously examined the antibacterial activity of Australian native plants, although there has recently been a substantial increase in interest in this field. ${ }^{21-24}$ The genus Westringa (family Lamiaceae) consists of more than 30 species of Australian shrubs. ${ }^{25}$ Westringa fruticosa (Willd.) Druce (commonly known as coastal rosemary) is an endemic Australian shrub (Figure 1a) that grows in coastal regions of Eastern Australia. Its growth pattern resembles Rosmarinus officinalis L. (rosemary) and both species are in the same family. W. fruticosia flowers in spring and summer in temperate southern climates but can flower continuously in warmer climates. The flowers are small (2-1mm long) and are white in colour with purple to brown dots (Figure 1b).

In contrast with many other members of family Lamiaceae, there is little evidence that $W$. fruticosa was used medicinally by the first Australians. However, a recent study reported potent growth inhibitory activity for W. fruticosa leaf extracts against Listeria monocytogenes, Micrococcus luteus and Staphylococcus aureus. ${ }^{26}$ The same study reported lower activity or no activity at all against against Bacillus subtilis, Escherichia coli, Klebsiellia pneumonia Pseudomonas aeruginosa and Salmonella typhimurium. In contrast, a different study reported that W. fruticosa leaf and flower extracts were completely ineffective against Aeromonas hydrophilia, Pseudomonas fluorescens, Bacillus cereus and Bacillus subtilis. ${ }^{27}$ There is also a lack of information on the phytochemical composition of this species. However, the phytochemistry of other Laminacaeae species has been reported ${ }^{28}$ and is characterised by relatively high levels of luteolin-7- rutinoside (Figure 1c), luteolin-7-glucuronide (Figure 1d), lithospermic acid (Figure 1e), rosmarnic acid (Figure 1f) and methyl rosmarinate (Figure 1g). Many of these compounds have been reported to have potent antibacterial activity ${ }^{29}$ and may therefore contribute to the antibacterial properties of $W$. fruticosa. This study was 


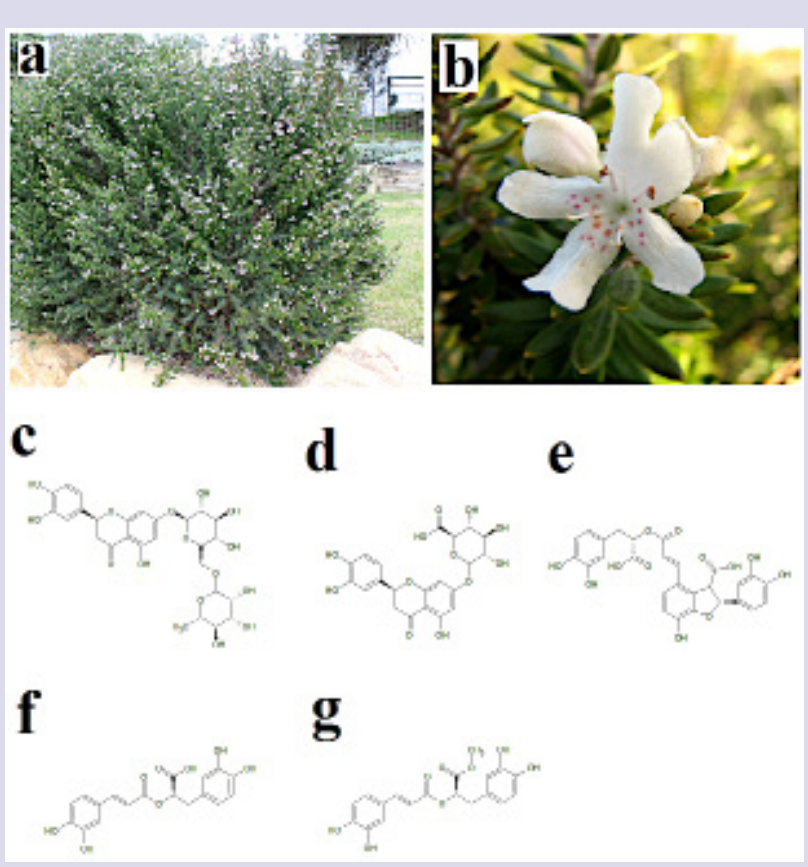

Figure 1: W. fruticos $a(a)$ whole plant and (b) flower and the structures of some common Lamiacaeae compounds: (c) luteolin7- rutinoside, (d) luteolin-7-glucuronide, (e) lithospermic acid, (f) rosmarnic acid and (g) methyl rosmarinate.

undertaken to screen $W$. fruticosa leaf and flower extracts for the ability to inhibit the growth of a panel of gram-positive and gram-negative bacterial pathogens and three fungi.

\section{MATERIALS AND METHODS}

\section{Plant material}

\section{Collection of plant material and extraction}

Westringa fruticosa (Willd.) Druce leaves and flowers were harvested from a confirmed suburban plant in the southern suburbs of Brisbane, Australia. The plant was monitored for 3 months prior to harvesting to ensure that it received no pesticides or fertilisers and none were used in a 3-metre radius of the plant. The harvested leaves and flowers were washed in deionised water and processed within $4 \mathrm{~h}$ of collection. The leaves were dried in a Sunbeam food dehydrator and the dried material was ground to a coarse powder. Individual $1 \mathrm{~g}$ masses of the dried plant material was extracted extensively in $50 \mathrm{~mL}$ methanol (Ajax, AR grade) or deionised water for $24 \mathrm{~h}$ at $4^{\circ} \mathrm{C}$ with gentle shaking. The extract was filtered through filter paper (Whatman No. 54) under vacuum followed by drying by rotary evaporation. The resultant pellet was dissolved in $5 \mathrm{~mL}$ deionised water. The extract was passed through $0.22 \mu \mathrm{m}$ filter (Sarstedt) and stored at $4^{\circ} \mathrm{C}$.

\section{Qualitative phytochemical studies}

Phytochemical analysis of the $W$. fruticosa leaf extracts for the presence of saponins, phenolic compounds, flavonoids, phytosteroids, triterpenoids, cardiac glycosides, anthraquinones, tannins and alkaloids was conducted by standard assays. ${ }^{30-32}$

\section{Antibacterial screening \\ Test microorganisms}

All media was purchased from Oxoid Ltd., Australia. The reference strains of Escherichia coli (ATCC157293), Klebsiella pneumoniae (ATCC31488), Proteus mirabilis (ATCC21721) and Streptococcus pyogenes (ATCC19615) were purchased from American Tissue Culture Collection (ATCC), USA. Clinical isolate microbial strains of Aeromonas hydrophilia, Alcaligenes feacalis, Aspergillus niger, Bacillus cereus, Candida albicans, Citrobacter freundii, Pseudomonas fluorescens, Saccromyces cerviseae, Salmonella newport, Serratia marcescens, Shigella sonneii, Staphylococcus aureus and Staphylococcus epidermidis strains were obtained from Ms Michelle Mendell and Ms Jane Gifkins, Griffith University. All bacterial stock cultures were subcultured and maintained in nutrient broth at $4^{\circ} \mathrm{C}$. The fungal strains were cultured in Sabourand broth (Oxoid, Australia).

\section{Evaluation of antimicrobial activity}

Antimicrobial activity of the $W$. fruticosa leaf extracts was determined using a modified disc diffusion assay. ${ }^{33-35}$ Briefly, $100 \mu \mathrm{L}$ of the each microbial suspension in log phase was spread onto individual nutrient agar plates (or Sabourand agar for the fungal strains) and the extracts were tested for antimicrobial activity using $6 \mathrm{~mm}$ sterilised filter paper discs. The discs were each infused with $10 \mu \mathrm{L}$ of the individual plant extract, allowed to dry and placed onto the inoculated plates. The plates were allowed to stand at $4^{\circ} \mathrm{C}$ for $2 \mathrm{~h}$ before incubation at $37^{\circ} \mathrm{C}$ for $24 \mathrm{~h}$. The diameters of the zones of inhibition (ZOIs) were measured to the closest whole millimetre. Each assay was performed three times in triplicate $(n=9)$. Mean values $( \pm$ SEM) are reported in this study. Standard discs of ampicillin $(10 \mu \mathrm{g})$, chloramphenicol $(10 \mu \mathrm{g})$ and nystatin $(100 \mu \mathrm{g})$ were obtained from Oxoid, Australia and were used as positive controls to compare antibacterial and antifungal activity. Filter discs infused with $10 \mu \mathrm{L}$ of distilled water were used as a negative control.

\section{Artemia franciscana nauplii toxicity screening}

Toxicity was tested using an adapted Artemia franciscana nauplii lethality assay. ${ }^{36-38}$ Briefly, $A$. franciscana nauplii were incubated in the presence of the extracts, reference toxin $(1 \mathrm{mg} / \mathrm{mL}$ potassium dichromate) or artificial seawater (negative control) at $25 \pm 1{ }^{\circ} \mathrm{C}$ under artificial light. All treatments were performed three times in triplicate $(n=9)$. The number of dead were counted in each well at $24 \mathrm{~h}, 48 \mathrm{~h}$ and $72 \mathrm{~h}$. At the completion of the $72 \mathrm{~h}$ exposure period, the remaining live nauplii were sacrificed and the total number of nauplii in each well were counted and used to calculate the $\%$ mortality per well. LC $_{50}$ values were calculated for each treatment using probit analysis.

\section{Statistical analysis}

Data are expressed as the mean \pm SEM of three independent experiments with internal triplicates $(n=9)$. One-way ANOVA was used to calculate statistical significance between control and treated groups, with a $P$ value $<0.01$ considered to be statistically significant.

\section{RESULTS}

\section{Liquid extraction yields and qualitative phytochemical screening}

Extraction of $1 \mathrm{~g}$ of dried and powdered W. fruticosa leaves with methanol and water yielded 279 and $224 \mathrm{mg}$ of extracted material respectively (Table 1). The extracts were resuspended in $10 \mathrm{~mL}$ of deionised water (containing 1\% DMSO), resulting in the extract concentrations shown in Table 1. Qualitative phytochemical studies showed that both leaf extracts had similar phytochemical profiles. Both contained high levels 
Table 1: The mass of dried extracted material, the concentration after resuspension in deionised water and qualitative phytochemical screenings of the W. fruticosa leaf.

\begin{tabular}{|c|c|c|c|c|c|c|}
\hline & & & \multicolumn{2}{|c|}{ Leaf } & \multicolumn{2}{|c|}{ Flower } \\
\hline & & & $\begin{array}{c}\text { Methanolic } \\
\text { extract }\end{array}$ & $\begin{array}{l}\text { Aqueous } \\
\text { extract }\end{array}$ & $\begin{array}{c}\text { Methanolic } \\
\text { extract }\end{array}$ & $\begin{array}{c}\text { Aqueous } \\
\text { extract }\end{array}$ \\
\hline \multicolumn{3}{|c|}{ Mass of extracted material (mg) } & 279 & 224 & 283 & 216 \\
\hline \multicolumn{3}{|c|}{ Concentration of resuspended extract $(\mathrm{mg} / \mathrm{mL})$} & 27.9 & 22.4 & 28.3 & 21.6 \\
\hline \multirow{3}{*}{\multicolumn{2}{|c|}{ Phenols }} & Total phenols & +++ & +++ & +++ & +++ \\
\hline & & Water soluble phenols & +++ & +++ & +++ & +++ \\
\hline & & Insoluble phenols & ++ & ++ & ++ & ++ \\
\hline \multirow{2}{*}{\multicolumn{2}{|c|}{ Saponins }} & Froth persistence & - & - & + & + \\
\hline & & Emulsion test & - & - & + & + \\
\hline \multirow{11}{*}{$\begin{array}{c}\text { Qualitative } \\
\text { Phytochemical Tests }\end{array}$} & Cardiac glycosides & Keller-Kiliani Test & - & - & - & - \\
\hline & Triterpenoids & Salkowski Test & + & - & - & - \\
\hline & Phytosterols & Acetic Anhydride Test & - & - & - & - \\
\hline & \multirow{3}{*}{ Alkaloids } & Meyer's Test & - & - & - & - \\
\hline & & Wagner's Test & - & - & - & - \\
\hline & & Draggendoff's Test & - & - & - & - \\
\hline & Flavonoids & Kumar Test & +++ & +++ & +++ & +++ \\
\hline & \multirow{2}{*}{ Tannins } & Ferric Chloride Test & ++ & ++ & + & + \\
\hline & & Lead Acetate Test & + & - & + & + \\
\hline & \multirow{2}{*}{ Anthraquinones } & Free & - & - & - & - \\
\hline & & Combined & - & - & - & - \\
\hline
\end{tabular}

+++ indicates a large response; ++ indicates a moderate response; + indicates a minor response; - indicates no response in the assay.

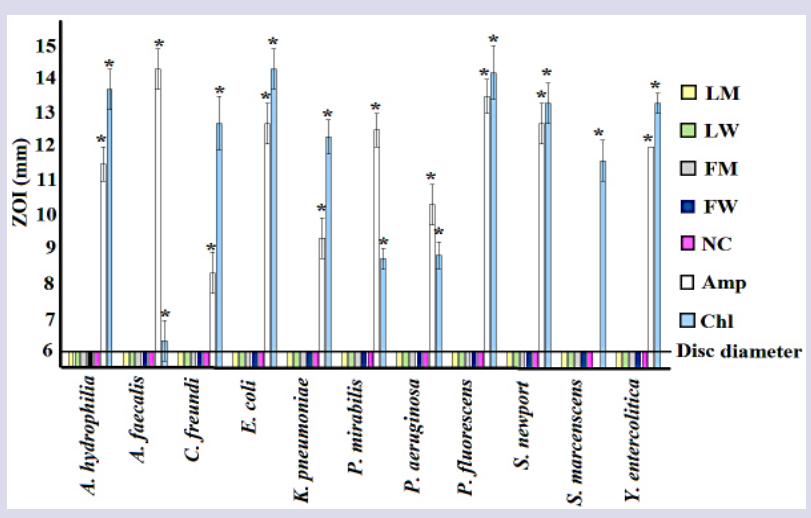

Figure 2: Growth inhibitory activity of $W$. fruticosa leaf and flower extracts and reference antibiotics against gram-negative bacterial species measured as ZOls $(\mathrm{mm}) \pm \mathrm{SEM}$. $\mathrm{L}=$ leaf; $\mathrm{F}=$ fruit; $\mathrm{M}=$ methanolic extract; $\mathrm{W}=$ aqueous extract; $\mathrm{Amp}=$ ampicillin $(10 \mu \mathrm{g}) ; \mathrm{Chl}=$ chloramphenicol $(10 \mu \mathrm{g})$; $\mathrm{NC}=$ negative control. All assays were completed three times, each with internal triplicates $(n=9)$ and the results are expressed as mean zones of inhibition $(\mathrm{mm}) \pm$ SEM.

of phenolic compounds and flavonoids, as well as moderate levels of tannins. Similar yields of dried extracted material were obtained for the $W$. fruticosa flower extracts. The flower extracts also had similar phytochemical profiles to the leaf extracts, albeit generally with lower relative abundance.

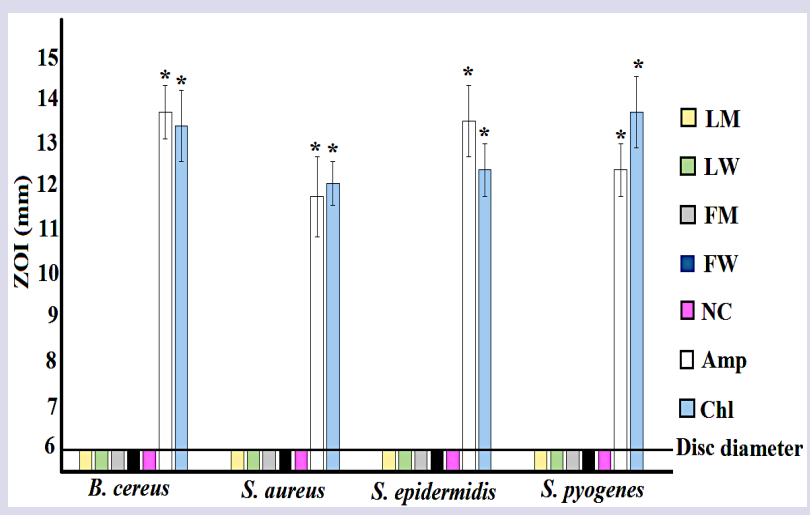

Figure 3: Growth inhibitory activity of $W$. fruticosa leaf extracts and reference antibiotics against gram-positive bacterial species measured as ZOls $(\mathrm{mm}) \pm \mathrm{SEM}$. $\mathrm{L}=$ leaf; $\mathrm{F}=$ fruit; $\mathrm{M}=$ methanolic extract; $\mathrm{W}=$ aqueous extract; $\mathrm{Amp}=$ ampicillin $(10 \mu \mathrm{g}) ; \mathrm{Chl}=$ chloramphenicol $(10 \mu \mathrm{g}) ; \mathrm{NC}=$ negative control. All assays were completed three times, each with internal triplicates $(n=9)$ and the results are expressed as mean zones of inhibition $(\mathrm{mm}) \pm \mathrm{SEM}$.

\section{Antimicrobial activity}

To determine the growth inhibitory activity of the $W$. fruticosa leaf and flower extracts, aliquots $(10 \mu \mathrm{L})$ of each extract were screened in the disc diffusion assay. The $W$. fruticosa leaf and flower extracts were ineffective at inhibiting the growth of all gram-negative (Figure 2) and gram positive (Figure 3) bacterial species tested. In contrast, both positive control antibiotics (ampicillin and chloramphenicol) were effective 


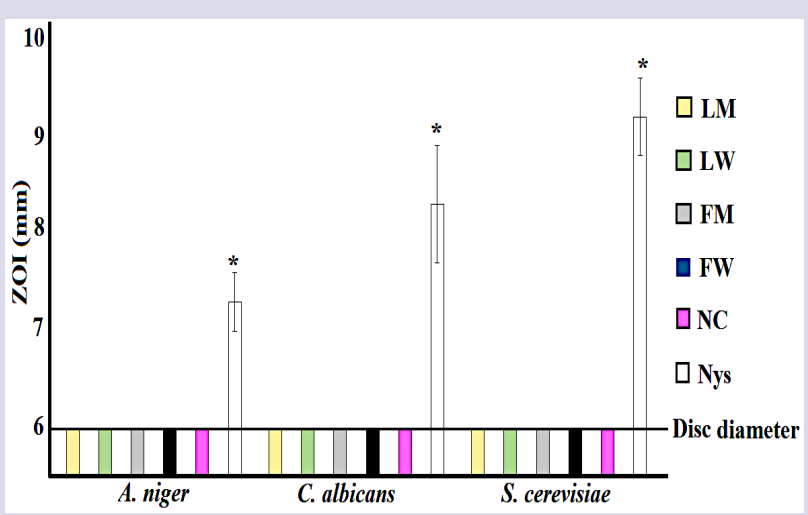

Figure 4: Growth inhibitory activity of $W$. fruticosa leaf extracts and reference antibiotics against fungal species measured as ZOIs $(\mathrm{mm})$ \pm SEM. $L=$ leaf; $F=$ fruit; $M=$ methanolic extract; $W=$ aqueous extract; Nys = Nystatin $(100 \mu \mathrm{g})$; $\mathrm{NC}=$ negative control. All assays were completed three times, each with internal triplicates $(n=9)$ and the results are expressed as mean zones of inhibition $(\mathrm{mm}) \pm \mathrm{SEM}$.

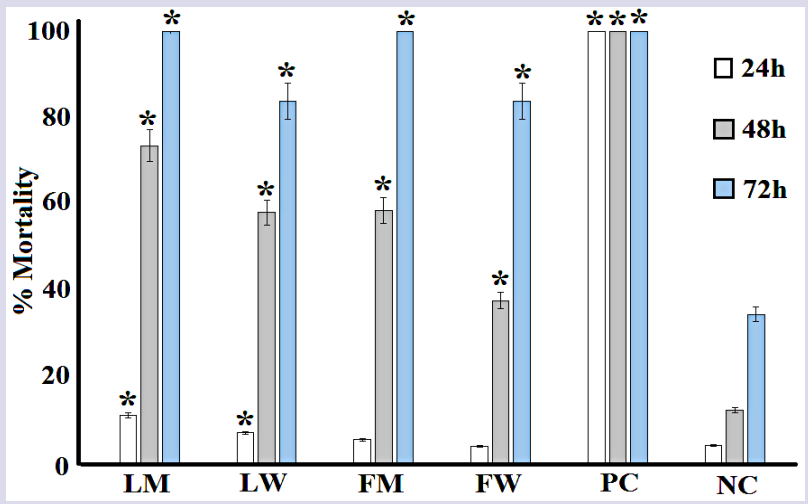

Figure 5: The lethality of the $W$. fruticosa leaf and flower extracts, potassium dichromate control $(\mathrm{PC} ; 1000 \mu \mathrm{g} / \mathrm{mL})$ and seawater negative control (NC) following 24,48 and $72 \mathrm{~h}$ of exposure. $\mathrm{L}=$ leaf; $\mathrm{F}=$ flower; $\mathrm{M}=$ methamolic extract; $\mathrm{W}=$ aqueous extract. All bioassays were performed three times in triplicate $(n=9)$ and are expressed as mean \pm SEM. * indicates results that are significantly different to the untreated (seawater) control at the equivalent exposure time $(\mathrm{P}<0.01)$.

growth inhibitors, with ZOI's of up to $14.3 \mathrm{~mm}$ (chloramphenicol against E. coli). We were therefore unable to determine the MIC values for any extract as they were completely ineffective at all concentrations tested. Similarly, all of the extracts were ineffective at inhibiting the growth of the three fungal species screened in this study (Figure 4).

\section{Quantification of Toxicity}

The toxicity of the $W$. fruticosa leaf and flower extracts was initially tested at $2 \mathrm{mg} / \mathrm{mL}$ in the A. franciscana nauplii bioassay (Figure 5). The mortality in the presence of all extracts was not significantly different to that of the untreated control at $24 \mathrm{~h}$ and thus were deemed to be non-toxic. Extracts with $24 \mathrm{~h} \mathrm{LC}_{50}$ values $>1000 \mu \mathrm{g} / \mathrm{mL}$ have previously been defined as non-toxic. ${ }^{38}$ In contrast, the potassium dichromate positive control induced substantial mortality within $4 \mathrm{~h}$ (results not shown), with $100 \%$ mortality induction seen by $24 \mathrm{~h}$. The mortality increased following exposure to the $W$. fruticosa leaf extracts at $48 \mathrm{~h}$ and was further increased following $72 \mathrm{~h}$ exposure.

\section{DISCUSSION}

Due to recent increases in bacterial resistance to many antibiotics, the development of new antibiotic chemotherapies is a high priority for medical science. ${ }^{17,18} \mathrm{~A}$ concurrent decrease in the discovery of new antibiotic medicines by conventional strategies has increased interest in re-evaluating medicinal plants for new antibiotic chemotherapies. ${ }^{39}$ Whilst we were unable to find reports of the traditional use of W. fruticosa medicinally, it is taxonomically related to other Lamiaceae species with extensive therapeutic uses. For example, Mentha piperita L. (peppermint), Melissa officinalis L. (Melissa leaf, lemon balm leaf) and Salvia officinalis L. (sage) have widespread uses as herbal teas and essential oils. M. piperita is used topically for muscle and nerve pain and for the relief of itching. Oral administration is useful for relieving gastrointestinal complaints. ${ }^{40} M$. officinalis and Salvia officinalis are used for disorders of the gastrointestinal tract, nervous system, as well as liver and bile disorders. ${ }^{28}$ Many of these diseases are caused by bacterial infections and numerous studies have reported antibacterial properties for species of this genus. ${ }^{41-43}$ However, many of these studies either do not quantify the activity, or report low to moderate activity for the extracts and oils of these plants.

The antibacterial activity of Australian Lamiaceae species is even less well examined. Indeed, we were only able to find two studies examining the antibacterial activity of $W$. fruticosa. One study reported that a $W$. fruticosa leaf extract was a potent inhibitor of L. monocytogenes, $M$. luteus and $S$. aureus growth in a disc diffusion assay. ${ }^{26}$ The same extract was inactive or had only low activity against B. subtilis, E. coli, $K$, pneumonia P. aeruginosa and S. typhimurium. This contrasts with the results of our current study, which determined that $W$. fruticosa leaf and flower extracts were completely ineffective against an extended panel of bacteria. These results more closely align with a previous study from our group that screened $W$. fruticosa leaf and flower extracts against A. hydrophilia, P. fluorescens, B. cereus and B. subtilis. The W. fruticosa extracts were completely ineffective at inhibiting the growth of those bacteria. ${ }^{27}$

A single assay technique was used to screen for antibacterial activity in this study (as well as in the previous studies examining the antibacterial activity of this species). We chose to use the disc diffusion assay as it is a rapid method and it has previously been widely utilised in other studies. Therefore, comparisons between studies are relatively simple. However, as the disc diffusion method is reliant on the diffusion of a molecule through the aqueous environment of an agar gel, this assay may be affected by the solubility of the extract compounds in the aqueous environment. Polar compounds that are highly soluble in water would be expected to diffuse easily in the gel, whereas less soluble compounds would not diffuse as readily and thus be concentrated around the disc. Diffusion of molecules within an agar gel is also affected by the size of the molecules. The movement of large, complex phytochemicals (eg. complex tannins) through agar gels by diffusion would also be retarded and may provide a false idea of the efficacy of an extract. As many tannins have well described antibiotic properties, screening for growth inhibition using agar diffusion techniques may give a fallacious view of its inhibitory potential. For this reason, whilst this is a handy assay for screening aqueous extracts, this technique may not be ideal for nonpolar compounds (e.g. when screening essential oils and their components). For examining nonpolar mixtures, other techniques such as liquid dilution assays may be preferred. As Lamiaceae spp. are known to contain nonpolar terpenoid components, ${ }^{44-46}$ their activity may have been significantly underestimated. Liquid dilution studies may 
have been better suited to screen $W$. fruticosa extracts for activity and future studies will use these techniques to re-examine the extracts for antibacterial activity.

The findings reported here also indicate that the extracts examined were non-toxic $\left(24 \mathrm{~h} \mathrm{LC}_{50}>1000 \mu \mathrm{g} / \mathrm{mL}\right)$ in the Artemia nauplii bioassay. Whilst toxicity was assessed in this study with the test organism A. franciscana, toxicity towards $A$. franciscana has previously been shown to correlate well with toxicity towards human cells for many toxins. ${ }^{38}$ However, further studies are required to determine whether this is also true for the $W$. fruticosa leaf extracts examined in these studies.

\section{CONCLUSION}

Methanolic and aqueous W. fruticosa leaf and flower extracts displayed no antibacterial activity in the disc diffusion assay against panels of human pathogenic bacteria and fungi, despite their close taxonomic relationship with other Laminaceae spp. with well-known antibacterial properties. The extracts were nontoxic towards Artemia nauplii.

\section{ACKNOWLEDGEMENT}

The authors are grateful to Michelle Mendell and Jane Gifkins of Griffith University for providing the clinical bacterial and fungal strains used in this study. Financial support for this work was provided by the Environmental Futures Research Institute, Griffith University, Australia.

\section{CONFLICT OF INTEREST}

The authors report no conflicts of interest.

\section{ABBREVIATIONS}

DMSO: Dimethyl sulfoxide; $\mathbf{L C}_{50}$ : The concentration required to achieve 50\% mortality; MIC: Minimum inhibitory concentration; ZOI: Zone of inhibition.

\section{REFERENCES}

1. Kamboj VP. Herbal medicine. Curr Sci. 2000;78(1):35-9

2. Hostettmann K, Hamburger M. Search for new lead compounds of natural origin. In Perspectives in Medical Chemistry. 1993

3. Wright MH, Sirdaarta J, White A, et al. GC-MS headspace analysis of Terminalia ferdinandiana fruit and leaf extracts which inhibit Bacillus anthracis growth. Pharmacog J. 2017;9(1):73-82. DOI:P 10.5530/pj.2017.1.14

4. Mpala LN, Chikowe GR, Cock IE. Growth inhibitory properties of extracts prepared from selected Leptospermum and Melaleuca species against a pane of pathogenic bacteria. Pharmacog Commn. 2016;6(4):215-24. DOI: 10.5530/ pc.2016.4.4

5. Omer E, Elshamy Al, Nassar M, et al. Plantago squarrosa Murray extracts inhibit the growth of some bacterial triggers of autoimmune diseases: GC-MS analysis of an inhibitory extract. Inflammopharmacol. 2018;1-3. DOI: 10.1007/ s10787-018-0547-0

6. Newman DJ, Cragg GM, Snader KM. The influence of natural products on drug discovery. Nat Prod Rep. 2000;17(3):215-34.

7. Gaillot C, Sirdaarta J, Cock IE. Examination of the antimicrobial and anticancer properties of mangosteen. Acta Horticulturae. 2016;1106:231-8.

8. Wright MH, Greene AC, Cock IE. Investigating the pharmacognostic potential of Indian Terminalia spp. in the treatment and prevention of yersiniosis. Pharmacog Commn. 2017;7(3):108-13. DOI: 10.5530/pc.2017.3.16

9. Gilani AH, Atta-ur-Rahman. Trends in ethnopharmacology. J Ethnopharmacol. 2005;100(1-2):43-9.

10. Hübsch Z, Zyl RLV, Cock IE, Vuuren SFV. Interactive antimicrobial and toxicity profiles of conventional antimicrobials with Southern African medicinal plants. South African Journal of Botany. South African Journal of Botany. 2014;93:185-97. DOI: 10.1016/j.sajb.2014.04.005

11. Cock IE, Vuuren SFV. Anti-Proteus activity of some South African medicinal plants: Their potential for the treatment and prevention of rheumatoid arthritis. Inflammopharmacol. 2014;22(1):23-36. DOI 10.1007/s10787-013-0179-3.

12. Omer E, Elshamy A, Gendy ANE, et al. Cakile maritima Scop. Extracts inhibit the growth of some bacterial triggers of autoimmune diseases: GC-MS analysis of an inhibitory extract. Pharmacog J. 2016;8(4):361-74. DOI: 10.5530/pj.2016.4.9
13. Biggs I, Sirdaarta J, White A, Cock IE. GC-MS analysis of Commiphora molmo oleo-resin extracts which inhibit the growth of bacterial triggers of selected autoimmune diseases. Pharmacog J. 2016;8(3):191-202. DOI: 10.5530/ pj.2016.3.4

14. Biggs I, Sirdaarta J, White A, Cock IE. GC-MS analysis of frankincense extracts which inhibit the growth of bacterial triggers of selected autoimmune diseases. Pharmacog Commn. 2016;6(1):10-22. DOI: 10.5530/pc.2016.1.3

15. Mohanty S, Cock IE. Evaluation of the antibacterial activity and toxicity of Myrciaria caulifloria methanolic leaf and fruit extracts. Int J Microbiol. 2009;7(2).

16. Cock IE. Medicinal and aromatic plants-Australia. In Ethnopharmacology Encyclopedia of Life Support Systems. 2011.

17. Cheesman MJ, Ilanko A, Blonk B, Cock IE. Developing new antimicrobial therapies: Are synergistic combinations of plant extracts/compounds with conventional antibiotics the solution?. Pharmacog Rev. 2017;11(2):57-72. DOI: 10.4103/phrev.phrev_21_17

18. WHO. Antimicrobial Resistance. World Health Organization. 2016.

19. Sirdaarta J, Matthews B, Cock IE. Kakadu plum fruit extracts inhibit the growth of the bacterial triggers of rheumatoid arthritis: Identification of stilbene and tannin components. J Funct Food. 2015;17:610-20. DOI: 10.1016/j.jff.2015.06.019

20. Ilanko A, Cock IE. The interactive antimicrobial activity of conventional antibiotics and Petalostigma spp. Extracts against bacterial triggers of some autoimmune inflammatory diseases. Pharmacog J. 2019;11(1).

21. Winnett $V$, Boyer H, Sirdaarta J, Cock IE. The potential of Tasmannia lanceolata as a natural preservative and medicinal agent: antimicrobial activity and toxicity. Pharmacognosy Communications. 2014:4(1):42-52. DOI: 10.5530/pc.2014.1.7

22. Cock IE. Antimicrobial activity of Callistemon citrinus and Callistemon salignus methanolic extracts. Pharmacog Commn. 2012;2(3):50-7. DOI: 10.5530/ pc.2012.3.11

23. Wright $\mathrm{MH}$, Lee $\mathrm{CJ}$, Pollock $\mathrm{CE}$, et al. Growth inhibitory activity of selected high antioxidant Australian Syzygium species against the food poisoning and tissue necrotic pathogen Clostridium perfringens. Pharmacog Commn. 2016;6(2):93-9. DOI: 10.5530/pc.2016.2.7

24. Wright $\mathrm{MH}$, Shalom J, Matthews B, et al. Terminalia ferdinandiana Exell. extracts inhibit Shewanella spp. growth and prevent fish spoilage. Food Microbiol. 2019:78:114-22. DOI:P 10.1016/j.fm.2018.10.006

25. Guerin GR. A revision of Westringia section Cephalowestringia (Lamiaceae: Westringieae). Aus Syst Bot. 2009;22(2):121-36.

26. Wigmore SM, Naiker M, Bean DC. Antimicrobial activity of extracts from native plants of temperate Australia. Pharmacog Commn. 2016;6(2):80-4

27. Cock IE. Antibacterial activity of selected Australian native plant extracts. Int J Microbiol. 2008;4(2):1-8

28. Fecka I, Turek S. Determination of polyphenolic compounds in commercial herbal drugs and spices from Lamiaceae: thyme, wild thyme and sweet marjoram by chromatographic techniques. Food Chem. 2008;108(3):1039-53.

29. Cock IE. The phytochemistry and chemotherapeutic potential of Tasmannia lanceolata (Tasmanian pepper): A review. Pharmacog Commn. 2013;3(4):1325. DOI: $10.5530 /$ pc.2013.4.3

30. Hart C, Ilanko P, Sirdaarta J, et al. Tasmannia stipitata as a functional food/ natural preservative: Antimicrobial cctivity and toxicity. Pharmacog Commn. 2014;4(4):33-47. DOI: 10.5530/pc.2014.4.4

31. Winnett $V$, Sirdaarta J, White A, et al. Inhibition of Klebsiella pneumonia growth by selected Australian plants: natural approaches for the prevention and management of ankylosing spondylitis. Inflammopharmacol. 2017;25(2):223-35. DOI: 10.1007/s10787-017-0328-1

32. Wright $\mathrm{MH}$, Matthews $\mathrm{B}$, Arnold MSJ, et al. The prevention of fish spoilage by high antioxidant Australian culinary plants: Shewanella putrefaciens growth inhibition. Int J Food Sci Tech. 2016;51(3):801-13. DOI: 10.1111/ijfs.13026

33. Mpala L, Chikowe G, Cock IE. No evidence of antiseptic properties and low toxicity of selected Aloe species. J Pharmaceut Neg Res. 2010;1(1):10-6.

34. Lee CJ, Wright MH, Arnold MSJ, et al. Inhibition of Streptococcus pyogenes growth by native Australian plants: New approaches towards the management of impetigo, pharyngitis and rheumatic heart disease. Pharmacog Commn. 2016;6(3):164-73

35. Wright $\mathrm{MH}$, Arnold MSJ, Lee $\mathrm{CJ}$, et al. Qualitative phytochemical analysis and antibacterial activity evaluation of Indian Terminalia spp. against the pharyngitis causing pathogen Streptococcus pyogenes. Pharmacog Commn 2016;6(2):85-92

36. Cock IE, Winnett V, Sirdaarta J, et al. The potential of selected Australian medicinal plants with anti-Proteus activity for the treatment and prevention of rheumatoid arthritis. Pharmacog Mag. 2015;11(Suppl 1):S190-208.

37. Hart C, Cock IE. An examination of the antimicrobial and anticancer properties of Garcinia cambogia fruit pericarp extracts. BEMS Reports. 2016;2(1):23-6.

38. Cock IE, Ruebhart DR. Comparison of the brine shrimp nauplii bioassay and the ToxScreen-II test for the detection of toxicity associated with Aloe vera (Aloe barbadensis Miller) leaf extract. Pharmacog Res. 2009;1(2):98-101.

39. Aiyegoro OA, Okoh Al. Use of bioactive plant products in combination with standard antibiotics: Implications in antimicrobial chemotherapy. J Med Plant 
Res. 2009;3(13):1147-52

40. Keifer D, Ulbricht C, Abrams T, et al. Peppermint (Mentha piperita): An evidencebased systematic review by the Natural Standard Research Collaboration. J Herbal Pharmacother. 2007;7(2):91-143.

41. Assis FV, Flavia L, Siqueira IE, et al. Antibacterial activity of Lamiaceae plant extracts in clinical isolates of multidrug-resistant bacteria. Anais da Academia Brasileira de Ciências. 2018. DOI: 10.1590/0001-3765201820160870.

42. Kozłowska MA, Laudy AE, Przybył JA, et al. Chemical composition and antibacterial activity of some medicinal plants from Lamiaceae family. Acta Pol Pharm. 2015;72(4):757-67.
43. Hussein AA. Chemistry of South African Lamiaceae: Structures and biological activity of terpenoids. In Terpenes and Terpenoids. 2018.

44. Abu RIM, Arráez RD, Al NM, et al. Untargeted metabolite profiling and phytochemical analysis of Micromeria fruticosa L. (Lamiaceae) leaves. Food Chem. 2019;279:128-43.

45. Khaled KN, Boulekbache ML, Madani K. Phytochemical screening of antioxidant and antibacterial activities of methanolic extracts of some Lamiaceae. Industria Crops and Products. 2014;61:41-8.

46. Hussain Al, Anwar F, Nigam PS, et al. Antibacterial activity of some Lamiaceae essential oils using resazurin as an indicator of cell growth. Food Sci Technol. 2011;44(4):1199-206.

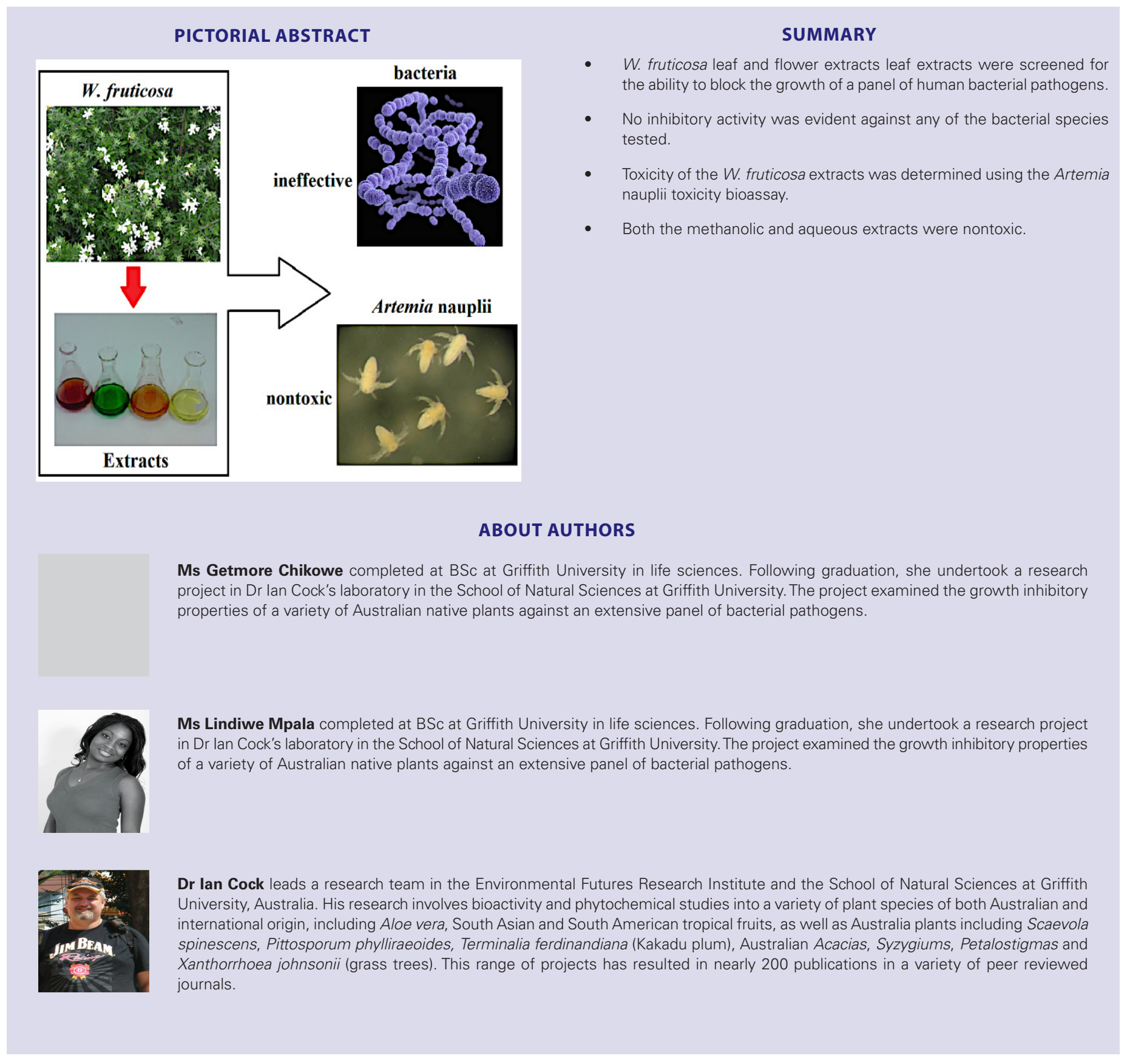

